\title{
Investor demand for IPOs and aftermarket performance: Evidence from the Hong Kong stock market
}

\author{
Sumit Agarwal ${ }^{\text {a }}$, Chunlin Liu ${ }^{\mathrm{b}, *}$, S. Ghon Rhee ${ }^{\mathrm{c}}$

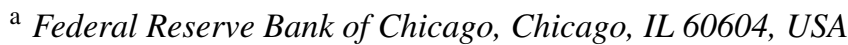 \\ ${ }^{\mathrm{b}}$ College of Business Administration, University of Nevada, Reno, NV 89557, USA \\ ${ }^{c}$ College of Business Administration, University of Hawaii, Honolulu, HI 96822, USA \\ Received 30 November 2005; accepted 1 September 2006 \\ Available online 17 October 2006
}

\begin{abstract}
In this study, we examine the relation between pre-offering demand and aftermarket performance of IPO firms in the Hong Kong stock market. We find that IPOs with high investor demand realize large positive initial returns but negative long-run excess returns, while IPOs with low investor demand realize negative initial returns but positive long-run excess returns. This result suggests that (1) pre-offering demand for IPOs is at least partly driven by investors' over- or underreactions to information about firms' post-issuance prospects, and (2) while high- and low-demand IPOs are not priced at their intrinsic values in early aftermarket trading, eventually their true values are reflected in their pricing.
\end{abstract}

(c) 2006 Elsevier B.V. All rights reserved.

JEL classification: G12; G14; G24

Keywords: Initial public offering; Aftermarket performance; Investor demand

\section{Introduction}

On average, initial public offerings (IPOs) of common stocks earn abnormally high initial returns (Ibbotson, 1975; Ritter, 1984; Loughran et al., 1994), but significantly underperform the market in the long run (3-5 years) (Aggarwal and Rivoli, 1990; Loughran and Ritter, 1995). These IPO return anomalies are observed in stock markets around the world. According to Ritter (1991), the short-run underpricing/long-run underperformance phenomenon represents an unresolved

\footnotetext{
* Corresponding author. Tel.: +1 $7757846993 \times 240$.

E-mail address: liuc@unr.edu (C. Liu).
} 
mystery in the IPO literature. ${ }^{1}$ Although these anomalies have prompted numerous academic researchers to investigate the causes of IPO underpricing, several puzzles remain. For instance: why are some IPOs underpriced while others are not, and why do underpriced IPOs underperform after they become seasoned? Moreover, little attention has been paid to the differences in long-run performance between those IPOs that are under- or over-priced.

In this study, we address these gaps in the literature by characterizing the relation between IPO firms' pre-offering demand and aftermarket performance. In particular, we are interested in the correlation between an IPO's demand and its initial stock return as well as its long-run return. Since investors' assessments result in downward-sloping demand curves for IPO stocks, investor demand should affect IPO performance.

Focusing mainly on the causes of IPO underpricing, the theoretical work of Rock (1986), Aggarwal and Rivoli (1990) and Chowdhry and Sherman (1996) provides predictions regarding this demand-performance relation. According to Rock (1986), informed investors with superior information have the ability to distinguish between "good" and "bad" IPOs. Hence, informed investors subscribe only to high quality issues, leading to high demand (demand of informed investors plus uninformed investors) for good IPOs and low demand (demand of only uninformed investors) for bad IPOs. Rock's hypothesis implicitly suggests, therefore, that high-demand IPOs exhibit relatively higher returns both during the first days of trading and in the long run. Chowdhry and Sherman (1996) also posit a positive relation between investor demand and underpricing of IPOs, arguing that a severely underpriced IPO will attract a large number of investors who seek to exploit the resulting short-run profit opportunities. Their model suggests that high-demand IPOs experience a relatively large positive return on the first post-IPO trading day, but that the difference in post-issuance performance between high- and low-demand IPOs occurs only in the short run, with mispricings potentially corrected rapidly in opening-day trading. Finally, Aggarwal and Rivoli (1990) argue that IPO underpricing may be positively related to long-run underperformance as a result of investor irrationality (see also Rajan and Servaes, 2002; Ljungqvist et al., 2007).

A number of empirical studies also find evidence consistent with a relation between investor demand and IPO performance. Hanley (1993) demonstrates that the relation between an IPO's offer price and preliminary filing range predicts the direction of initial stock returns in US stock markets. Cornelli and Goldreich (2003) find that oversubscription for an IPO is positively correlated with aftermarket returns. Kandel et al. (1999) document a positive relation between IPO demand schedules and abnormal returns on the first trading day for a small sample of Israeli IPOs. ${ }^{2}$ Overall, the above studies all indicate that pre-offering demand for IPOs plays a nontrivial role in the pricing of these IPOs the first trading day. However, it is worth pointing out that there is virtually no direct empirical evidence on the relation between the level of investor demand and the long-term performance of IPOs.

To study the relation between pre-IPO investor demand and post-IPO performance, we employ a unique data set for IPOs between 1993 and 1997 from the Stock Exchange of Hong Kong (SEHK), which provides oversubscription information at IPO offer prices. ${ }^{3}$ The Hong Kong IPO market is a suitable market for our study for two reasons. First, McGuinness $(1992,1993)$ reports that IPOs

\footnotetext{
${ }^{1}$ Ritter and Welch (2002) provide a comprehensive overview of current research on various aspects of IPOs.

2 An interesting finding in their paper is that the above relation holds even when IPO prices are determined by investors rather than issuers or underwriters.

${ }^{3}$ Since the demutualization and consolidation of the stock exchange, futures exchange, and clearing and settlement company in March 2000, the resulting Hong Kong Exchanges and Clearing Limited has been referred to by the acronym "HKEx". However, in this paper we use the acronym "SEHK", which was used during this paper's period of study.
} 
in Hong Kong earn abnormal returns in the first day of trading and significantly underperform the market in the long run, as is the case in other markets. Thus, the results are largely generalizable to other markets of interest. Second, it is well known that investor demand for IPOs is fairly volatile in the Hong Kong stock market. For instance, some hot IPOs are oversubscribed by as much as 1000 times the number of shares offered, whereas, some cold IPOs have to be postponed or even cancelled because of undersubscription. These large variations in subscription ratios provide us an excellent setting in which to study the relation between IPOs' investor demand and aftermarket performance.

Not surprisingly, we find evidence consistent with a strong relation between IPOs' pre-offering demand and both short- and long-run post-issuing performance. The IPOs with high investor demand realize large positive initial returns but negative longer-run excess returns, while the IPOs with low investor demand realize negative initial returns but perform relatively well in the longer run.

These results cannot be explained by the information asymmetry hypothesis or the underpricing hypothesis. Although these two hypotheses predict a positive relation between investor demand and IPO initial returns, neither hypothesis can explain the observed differences in long-run performance between high- and low-demand IPOs. However, our empirical results are consistent with the speculative bubble hypothesis. Investor demand for an IPO is largely driven by investors' overoptimistic or overpessimistic reactions to pre-offering information about an IPO's prospects. Consequently, both high- and low-demand IPOs are not priced at their intrinsic values in early aftermarket trading, but eventually their true values are reflected in their pricing.

The remainder of this paper is organized as follows. Section 2 provides a brief description of the data. Section 3 presents the results for the relation between IPO investor demand and short-run performance and Section 4 presents the results for the relation between IPO investor demand and long-run performance. Section 5 provides a discussion of the results. Finally, Section 6 presents the concluding remarks.

\section{Data description}

We obtain the data for this study from two sources: the SEHK and the Pacific-Basin Capital Markets (PACAP) Research Center. Beginning in 1995, the SEHK's Fact Books started to disclose offering prices, offering proceeds, and subscription ratios for all IPOs introduced during a given year. Prior to 1995, the Fact Books only provided information on funds raised from the issues and subscription ratios, but not offering prices. Accordingly, we collect offering prices from hard copies of the Capital Change Forms supplied by the SEHK to the PACAP Research Center. Stock prices and daily returns are also drawn from the PACAP-Hong Kong Database.

The mechanism for allocating IPO shares in Hong Kong is similar to those employed in the United Kingdom and other Asian markets including China, Singapore and Thailand, in that issuing firms and underwriters distribute shares randomly and equally across application orders collected in the subscription period. The offer's price range is set before investors can submit purchase orders. Hence, demand for a firm's shares is severely incomplete when the offer price is established. Our full sample consists of 256 IPOs during the period from 1993 to 1997. Panel A of Table 1 reports summary statistics for the entire sample. The mean (median) subscription ratio is slightly over 90 (23), suggesting a very active IPO market in Hong Kong. However, the level of investor demand for IPOs differs dramatically from one firm to another. For instance, the largest subscription ratio is 1276 times and the smallest ratio is only 0.22 times the number of shares offered. Although most IPOs in the Hong Kong stock market are oversubscribed, some 
Table 1

IPO sample description

\begin{tabular}{|c|c|c|c|c|c|c|c|c|c|c|}
\hline & \multirow[t]{2}{*}{ Number of IPOs } & \multicolumn{5}{|c|}{ Subscription ratio } & \multicolumn{2}{|c|}{$\begin{array}{l}\text { Offering proceeds } \\
\text { (HK\$ million) }\end{array}$} & \multicolumn{2}{|c|}{$\begin{array}{l}\text { Market capitalization (HK\$ } \\
\text { million) }\end{array}$} \\
\hline & & Mean & S.D. & Median & Maximum & Minimum & Mean & S.D. & Mean & S.D. \\
\hline \multicolumn{11}{|c|}{ Panel A: summary statistics for the sample } \\
\hline Overall & 256 & 91.36 & 162.00 & 23.12 & 1276.00 & 0.22 & 638 & 2193 & 1792 & 8673 \\
\hline \multicolumn{11}{|l|}{ By year } \\
\hline 1993 & 62 & 134.24 & 161.16 & 82.49 & 658.38 & 1.10 & 427 & 937 & 1201 & 2095 \\
\hline 1994 & 50 & 62.67 & 126.42 & 5.64 & 583.00 & 0.22 & 334 & 473 & 756 & 786 \\
\hline 1995 & 24 & 8.59 & 22.10 & 2.42 & 109.91 & 0.22 & 318 & 515 & 995 & 1905 \\
\hline 1996 & 43 & 55.86 & 74.99 & 23.24 & 260.95 & 0.66 & 723 & 1029 & 2158 & 3883 \\
\hline \multirow[t]{2}{*}{1997} & 77 & 121.09 & 218.71 & 35.20 & 1276.00 & 0.58 & 1058 & 3782 & 2984 & 15374 \\
\hline & & & & \multicolumn{2}{|c|}{$\begin{array}{l}\text { Low-demand } \\
\text { IPOs }(N=64)\end{array}$} & & \multicolumn{2}{|c|}{$\begin{array}{l}\text { Medium-demand } \\
\text { IPOs }(N=128)\end{array}$} & & $\begin{array}{l}\text { High-demand } \\
\text { IPOs }(N=64)\end{array}$ \\
\hline \multicolumn{11}{|c|}{ Panel B: summary statistics for three IPO portfolios } \\
\hline \multicolumn{4}{|c|}{$\begin{array}{l}\text { Mean } \\
\text { Median }\end{array}$} & \multicolumn{2}{|c|}{1.54} & & \multicolumn{2}{|c|}{33.28} & & 297.33 \\
\hline \multirow{2}{*}{\multicolumn{2}{|c|}{$\begin{array}{l}\text { Median } \\
\text { Market capitalization (HKS }\end{array}$}} & & & \multicolumn{2}{|c|}{1.27} & & \multicolumn{2}{|c|}{23.12} & & 226.89 \\
\hline & & ion) & & 1350 & & & 228 & & & 1250 \\
\hline \multicolumn{3}{|c|}{ Offering proceeds (HK\$ million) } & & \multicolumn{2}{|c|}{600.42} & & \multicolumn{2}{|c|}{778.46} & & 395.28 \\
\hline
\end{tabular}


IPOs do not generate enough demand and are canceled. IPO market activities in Hong Kong also fluctuate from one year to another. Both 1993 and 1997 are associated with relatively hot issuing markets, during which time more firms conduct IPOs and demand for the IPOs tends to be large. The average subscription ratios in 1993 and 1997 are 134 and 121 times, respectively. By contrast, in 1995, a relatively cool issuing market year, the average ratio is only 8.59. The number of IPOs for 1995 is about one-third of those reported for 1993 or 1997.

For the purpose of this study, we categorize the 256 IPOs into three groups sorted by level of investor demand. IPOs in the lowest subscription ratio quartile are assigned to the low-demand IPO portfolio, IPOs in the highest subscription ratio quartile are assigned to the high-demand IPO portfolio, and the rest of the IPOs are assigned to the medium-demand IPO portfolio. Panel B of Table 1 presents summary statistics for the three IPO portfolios. The level of investor demand for IPOs differs dramatically across the three IPO portfolios: the average subscription ratio is only 1.54 for the low-demand portfolio, whereas, the corresponding ratio is 297.33 for the high-demand portfolio. Interestingly, the offering proceeds of the high-demand portfolio are smaller than those of the low-demand portfolio, at HK \$395 million versus HK \$600 million, respectively.

\section{Investor demand and IPO initial returns}

To measure the initial returns on the first trading day, we calculate raw returns (IR $i$ ) using the formula:

$$
\mathrm{IR}_{i}=\frac{\left(P_{i}-S_{i}\right)}{S_{i}},
$$

where, for IPO firm $i, P_{i}$ is the closing price on the first trading day and $S_{i}$ is the subscription price. We then calculate the mean initial returns for each IPO portfolio. Since the market-adjusted rate of return is commonly used in the previous IPO literature, for comparability we also compute adjusted initial returns in excess of the market return by using the PACAP value-weighted Hong Kong market index. ${ }^{4}$

Panel A of Table 2 reports the first trading day returns (offer-to-close) for the three IPO portfolios. Overall, Hong Kong IPOs observe an average initial return of $20.76 \%$ during the 5year period from 1993 to 1997, suggesting substantial IPO underpricing. This finding is consistent with McGuinness (1992), who reports an average excess return of over 17\% between 1980 and 1990 in Hong Kong. Note that not all IPOs are severely underpriced, however. For instance, the low-demand IPOs earn negative initial returns of $-6.67 \%$, implying that those IPOs are actually overpriced. The high-demand IPOs, on the other hand, earn astonishing positive initial returns of $59.96 \%$.

Panel B of Table 2 reports the market-adjusted initial returns for the three IPO portfolios. The low-demand IPOs earn a negative initial return of $-7.09 \%$ in excess of the market portfolio return while the high-demand IPOs earn positive market-adjusted initial returns of $58.05 \%$. These preliminary statistics suggest a positive relation between investor demand and first-day returns. The significant difference in initial returns between the high- and low-demand IPO portfolios also suggests that investor demand may play a critical role in IPO pricing. However, note that the

\footnotetext{
${ }^{4}$ Care should be taken in interpreting the market-adjusted initial returns of Hong Kong IPOs. There is a period of about 2 weeks between the date when shares are issued and the date when stocks start trading. Ideally, computations of the market-adjusted initial return should take this factor into account. Here, the market return on the first trading date is employed to compute the market-adjusted initial return.
} 
Table 2

First-day returns

\begin{tabular}{|c|c|c|c|c|}
\hline & All IPOs $(N=256)$ & $\begin{array}{l}\text { Low-demand } \\
\text { IPOs }(N=64)\end{array}$ & $\begin{array}{l}\text { Medium-demand } \\
\text { IPOs }(N=128)\end{array}$ & $\begin{array}{l}\text { High-demand } \\
\text { IPOs }(N=64)\end{array}$ \\
\hline \multicolumn{5}{|c|}{ Panel A: first-day returns } \\
\hline Mean ( $t$-stat) & $20.76(7.66)^{* * *}$ & $-6.67(-4.35)^{* * *}$ & $14.87(6.26)^{* * *}$ & $59.96(8.06)^{* * *}$ \\
\hline Median & 9.50 & -4.72 & 9.58 & 40.84 \\
\hline \multicolumn{5}{|c|}{ Panel B: market-adjusted first-day returns } \\
\hline Mean ( $t$-stat) & $20.29(7.84)^{* * *}$ & $-7.09(-3.90)^{* * *}$ & $15.09(5.77)^{* * *}$ & $58.05(7.67)^{* * *}$ \\
\hline Median & 10.43 & -3.60 & 10.89 & 38.94 \\
\hline
\end{tabular}

Note: Panel A reports the first-day raw returns (offer-to-close) for the three IPO portfolios during the 5-year period 1993 to 1997. In Panel B, initial returns in excess of the market return are computed using the PACAP value-weighted market return for the Hong Kong market to adjust the initial raw returns.

*** Significant at $1 \%$ level.

low-demand IPO portfolio has a negative mean initial return. We find the negative mean initial return for the low-demand IPO portfolio is mainly driven by the undersubscribed IPOs within the portfolio. We identify 25 IPOs with subscription ratios less than one. Among them, 23 have negative initial returns, with a mean of $-17.96 \%$. The other two have positive returns but of less than $2 \%$ on the first trading date.

To assess the role of investor demand in IPO pricing in the Hong Kong market, we examine other determinants of IPO initial returns along with the oversubscription ratio in a multiple regression framework. Specifically, we run the following regression:

$$
\mathrm{IR}_{i}=\alpha_{0}+\alpha_{1} \text { Ratio }_{i}+\alpha_{2} \text { Size }_{i}+\alpha_{3} \text { Fund }_{i}+\alpha_{4} \text { S.D }_{\cdot i}+\alpha_{5} \text { DIV }_{i}+\alpha_{6} \text { Ind }_{i}+\alpha_{7} \text { Year }_{i}+\varepsilon_{i},
$$

where Ratio is the oversubscription ratio, Size is the natural logarithm of the issuing firm's market capitalization (inflation adjusted to the 1993 value), Fund is the natural logarithm of the offering proceeds (inflation adjusted to the 1993 value), S.D. is the standard deviation of daily returns for the 25 days after listing, DIV is the first annual cash dividend yield following the IPO, Ind is a series of industry dummy variables, Year is a series of IPO year dummy variables, and $i$ denotes the IPO firm.

The oversubscription ratio variable (Ratio) is included to test whether a positive relation exists between investor demand and IPO initial returns. We employ a number of proxies for the ex ante uncertainty surrounding IPO events, in particular, the standard deviation of daily stock returns between the close of the first trading day and the close of the 25th trading day (Ritter, 1984; McGuinness, 1992), firm size as measured by market capitalization, and adjusted net proceeds raised from the issue (Ritter, 1984). Following Michaely and Shaw (1994), we calculate the first cash dividend yield (DIV) after an IPO to signal the quality of the issuing firm. To control for the industry effects identified by Ibbotson and Jaffe (1975) and Ritter (1984), we use a series of industry dummy variables based on the SEHK industry code. Finally, year dummies are used to account for market conditions.

Table 3 reports cross-sectional regression results. The most remarkable result is that the oversubscription ratio is a strong predictor of initial returns. On average, every unit increase in the over-subscription ratio contributes to a $0.18 \%$ increase in initial returns. The positive coefficient estimated for Ratio is the only one that is statistically significant among independent variables 
Table 3

Investor demand as a predictor of IPOs' initial returns

\begin{tabular}{llc}
\hline Independent variables & Dependent variable: IR & $t$-Stat \\
\hline Intercept & 29.72 & 1.63 \\
Ratio & 0.18 & $14.83^{* * *}$ \\
Size & -1.13 & -0.28 \\
Fund & -1.41 & -0.40 \\
S.D. & 1.51 & 1.41 \\
Div & -0.03 & -0.04 \\
Ind dummy & Yes & \\
Year dummy & Yes & \\
Adj - $R^{2}$ & 0.51 & \\
\hline
\end{tabular}

Note: The dependent variable is the oversubscription ratio. Size is the natural logarithm of the issuing firm's market capitalization (inflation adjusted to the 1993 value). Fund is the natural logarithm of the offering proceeds (inflation adjusted to the 1993 value). S.D. is the standard deviation of daily returns for the 25 days following the listing. DIV is the first annual cash dividend yield after the issuance. Ind is a series of industry dummy variables and Year is a series of dummy variables indicating an IPO's year.

*** Significant at $1 \%$ level.

introduced in the regression. The positive relation between investor demand and IPO initial returns is consistent with the results reported by Hanley (1993), Kandel et al. (1999) and Cornelli and Goldreich (2003). Furthermore, the multivariate regression results in Table 3 are consistent with the results recorded by McGuinness (1992). The issue size is negatively related to initial returns and the 25-day standard deviation of daily stock returns is positively related to initial returns.

\section{Investor demand and IPO long-run excess returns}

\subsection{Investor demand and IPO long-run size-adjusted excess returns}

In this section, we examine the relation between IPO investor demand and long-run returns. Specifically, we measure the size-adjusted excess returns for longer buy-and-hold periods as follows:

$$
\mathrm{ER}_{i T}=R_{i T}-\mathrm{RR}_{i T},
$$

where, for IPO firm $i, \mathrm{ER}_{i T}$ is the $T$-period (from 1 month to 3 years) buy-and-hold excess return, $R_{i T}$ the $T$-period buy-and-hold return, and $\mathrm{RR}_{i T}$ is the $T$-period buy-and-hold return for the reference portfolio of IPO firm $i$.

Note that firm $i$ 's reference portfolio has to be carefully constructed, since there are three effects that need to be addressed, namely, the new listing bias, the rebalancing bias, and the size bias (Barber and Lyon, 1997). To control for the new listing bias, the reference portfolio only includes those stocks with at least a 3-year trading history. Next, to control for the size bias, all qualified stocks are sorted into five quintiles based on their market values at the beginning of period $T$, and only those stocks from the quintile in which firm $i$ 's size falls are eligible to be included in the reference portfolio. Finally, to control for the rebalancing bias, we calculate:

$$
\mathrm{RR}_{i T}=\sum_{j=1}^{N_{j}} \frac{R_{j T}}{N_{j}},
$$


Table 4

Size-adjusted excess returns for the longer buy-and-hold periods

\begin{tabular}{lcccc}
\hline & All IPOs & Low-demand IPOs & Medium-demand IPOs & High-demand IPOs \\
\hline 1-Month $(t$-stat) & $-2.17(-0.24)$ & $1.32(0.79)$ & $-2.00(-0.13)$ & $-5.98(-2.34)^{* *}$ \\
6-Month $(t$-stat) & $-7.26(-1.45)$ & $0.86(0.13)$ & $-5.32(-1.55)$ & $-20.30(-3.21)^{* * *}$ \\
12-Month ( $t$-stat) & $1.57(0.77)$ & $24.77(1.98)^{*}$ & $-2.70(-0.89)$ & $-11.30(-2.89)^{* * *}$ \\
24-Month ( $t$-stat) & $-27.68(-3.90)^{* * *}$ & $4.95(0.26)$ & $-32.30(-3.37)^{* * *}$ & $-50.25(-7.86)^{* * *}$ \\
36-Month ( $t$-stat) & $-48.03(-4.03)^{* * *}$ & $-54.00(-4.38)^{* * *}$ & $-34.28(-4.03)^{* * *}$ & $-71.28(-8.09)^{* * *}$ \\
\hline
\end{tabular}

Notes: This table reports the size-adjusted excess returns for the holding periods between 1 month and 3 years. The beginning dates of buy-and-hold periods are the IPOs' second trading day.

* Significant at $10 \%$ level.

** Significant at $5 \%$ level.

*** Significant at $1 \%$ level.

where $N_{j}$ is the number of stocks included in firm $i$ 's reference portfolio, and $R_{j T}$ is the $T$-period buyand-hold return for stock $j$. The return on this portfolio represents an equally weighted investment in all stocks constituting the reference portfolio in period $T$. Another issue in the calculation of buy-and-hold returns for the reference portfolio arises when an investor places the proceeds of investments in firms delisted subsequent to period $T$. Here, it is assumed that the proceeds of delisted firms are invested in an equally weighted reference portfolio. Thus, missing monthly (daily) returns are filled with the mean monthly (daily) return of firms comprising of the reference portfolio.

After obtaining $\mathrm{ER}_{i T}$ for all IPOs, we calculate the means of the size-adjusted excess returns for the three IPO portfolios, as summarized in Table 4. The table reports the size-adjusted excess returns for the periods between 1 month and 3 years. The beginning dates of buy-and-hold periods are the IPOs' second trading days.

Several interesting findings emerge from Table 4. First, as a group, all IPOs exhibit 1-, 6, and 12-month excess returns of $-2.17 \%,-7.26 \%$, and $1.57 \%$, respectively, all statistically insignificant. These results are consistent with the findings reported by McGuinness (1993), who shows that the excess returns of Hong Kong stocks issued during the period of 1980 and 1990 are insignificantly different from zero within the first 12 months of listing. When the performance period is extended to 2 and 3 years, respectively, ${ }^{5}$ IPO firms underperform their peers significantly after excluding first trading day returns. For instance, the 2- and 3-year size-adjusted excess returns for the overall sample are $-27.68 \%$ and $-48.03 \%$, respectively.

Second, Table 4 reveals an interesting difference in the size-adjusted excess returns between high- and low-demand IPOs. After excluding first trading day returns, the high-demand IPO portfolio observes a 1-month return of $-5.98 \%$, which is statistically significant at the $5 \%$ level, while the corresponding return for the low-demand IPO portfolio is an insignificant $1.32 \%$. The underperformance of the high-demand IPO portfolio becomes more pronounced with longer examination periods. Its 6- and 12-month size-adjusted returns are $-20.30 \%$ and $-11.30 \%$, respectively, both significant at the $1 \%$ level. In contrast, the low-demand IPO portfolio observes a statistically significant return of $24.77 \%$ when the period is extended to 12 months. The difference in the size-adjusted excess returns between high- and low-demand IPOs continues to hold when the performance period is extended to even longer than a year. The low-demand IPO portfolio

\footnotetext{
${ }^{5}$ Due to data availability constraints, we are unable to examine performance over the 5-year period. Only a few IPOs in our sample have a performance history of more than 5 years.
} 
observes a 2-year return of $4.95 \%$, although it is not significant, while the corresponding return for the high-demand IPO portfolio is $-50.25 \%$, statistically significant at the $1 \%$ level.

As the performance period is extended to 3 years, both the high- and low-demand IPO portfolios produce negative returns of $-71.28 \%$ and $-54.00 \%$, respectively. This suggests that the high- and low-demand IPOs significantly underperform their corresponding reference portfolios (or market portfolio) over a 3-year buy-and-hold period. Interestingly, the 3-year performance results seem to suggest a much weaker relation between IPOs' investor demand and long-run performance. ${ }^{6}$ Although the widely accepted rule is to measure IPO long-run performance over periods of 3-5 years, caution is in order in interpreting the above results. The focus of this study is to investigate whether and how pre-offering investor demand for an IPO affects the IPO's aftermarket performance. That is, the question of interest is how long the impact will last if it exists in the first place. Although there is no way to ascertain the true duration of the impact, we doubt that a period of several years is a reasonable time horizon. Our rationale is as follows. Pre-offering demand for a particular IPO ultimately is transformed into trading demand for the firm's stock once the stock is listed on the stock exchange. In early trading, the trading demand for the stock is closely related to the pre-offering demand for the IPO. In other words, strong demand for an IPO prior to the offering is most likely to lead to strong demand for the stock after the offering. However, the strength of this relation is likely to dissipate over time, to the extent that trading demand for a stock reflects the fact that investors continuously update their beliefs about the firm's prospects as new information arrives. It is therefore hard to justify the view that pre-offering investor sentiment about an IPO can influence trading in the firm's stock beyond several years.

Overall, the results in Table 4 indicate that the high-demand IPOs significantly underperform their corresponding reference portfolios (or market portfolio) over buy-and-hold periods of 1 month to 3 years. However, the low-demand IPOs tend to overperform their corresponding reference portfolios when the performance period is less than 2 years. Clearly, the superior performance that IPOs with high investor demand observe in the first trading day does not sustain, as their excess return quickly turns negative over the subsequent 1 month to 3 years. In contrast, although the IPOs with low demand experience lower first-day returns, they perform well over longer buy-and-hold periods.

\subsection{Investor demand as a predictor of IPOs' long-run returns}

To assess the relation between IPOs' pre-offering demand and long-run performance after taking into account the effects of confounding factors, we perform two sets of multivariate regressions. In the first set, we examine whether investor demand can predict IPOs' long-run excess returns. The regression model is similar to that used for the first-day return regression, except that we include the first-day return (IR) as one of the independent variables in the regression, taking into account Affleck-Graves and Spiess' (1995) result that first-day IPO returns predict 3-month aftermarket performance. In addition, we include a dummy variable (FIN) that takes into account the effect of new financing, such as SEOs and private placements. We find that the frequency of the above events greatly increases after 1 year of the initial listing of a firm's stock. Consider

\footnotetext{
6 As a matter of fact, measuring annual returns, low-demand IPOs outperform high-demand IPOs in the first 2 years but underperform in the third year. The reason the excess return for low-demand IPOs becomes so negative in the third year is largely due to the fact that the return on the reference portfolio is very high in the third year. If measured by the raw returns, low-demand IPOs observe similar performance compared to high-demand IPOs ( $-17 \%$ versus $-14 \%)$. We are grateful to the referee for alerting us to this fact.
} 
private placements, which are a very popular vehicle for raising financing in the Hong Kong stock market. We find that at least 44 firms in our sample conduct private placements once we extend the performance period to 3 years. Thus, it is necessary to control for the effect of these corporate events on performance when inferring the relation between an IPO's pre-offering demand and long-run performance. Formally, the first set of regressions we run is as follows:

$$
\begin{aligned}
\mathrm{ER}_{i}= & \beta_{0}+\beta_{1} \text { Ratio }_{i}+\beta_{2} \text { Size }_{i}+\beta_{3} \text { Fund }_{i}+\beta_{4} \mathrm{IR}_{i}+\beta_{5} \mathrm{DIV}_{i}+\beta_{6} \mathrm{FIN}_{i}+\beta_{7} \operatorname{Ind}_{i} \\
& +\beta_{8} \text { Year }_{i}+\mu_{i} .
\end{aligned}
$$

Table 5 presents the results. As the table indicates, both investor demand and initial returns are negatively related to long-run IPO excess returns. For instance, Ratio's statistically significant and negative coefficients for the 6-, 12-, and 24-month holding periods suggest that investors who invest in the high-demand IPO portfolio immediately after the first trading date earn significantly less than the market portfolio even if the same IPOs observe high positive returns the first trading day. In contrast, investments in the low-demand IPO portfolio can expect to gain abnormal returns in the 6 months to 2 years after the offering. Note that a negative coefficient for 36-month holding period also results, even though it is insignificant. This is mainly due to the fact that the low-demand IPO portfolio overperforms the market while the high-demand IPO portfolio underperforms the market for observation periods of less than 2 years. However, both low- and high-demand IPO portfolios underperform the market for observation periods longer than 2 years, though the underperformance is much worse for the high-demand IPOs. This suggests a weak relation between investor demand and the 3-year holding period excess return.

\subsection{Calendar time portfolio regression results}

In the second set of tests, we run calendar time-based portfolio regressions. We demonstrate above that high-demand IPOs generally underperform low-demand IPOs over the longer buy-andhold periods. However, when measuring excess returns we control only for size in our buy-andhold return analysis. Lyon et al. (1999) advocate the use of the Fama-French three-factor model using calendar time portfolios to estimate long-run abnormal performance. This approach controls for the nonindependence of returns over time, size, and book-to-market effects, and avoids the problem associated with drawing inferences on skewed long-horizon returns. Accordingly, we estimate the three-factor model:

$$
R_{\mathrm{p} t}-R_{\mathrm{f} t}=\gamma_{0}+\gamma_{1}\left(R_{\mathrm{m} t}-R_{\mathrm{f} t}\right)+\gamma_{2} \mathrm{SMB}_{t}+\gamma_{3} \mathrm{HML}_{t}+\eta_{t},
$$

where, suppressing the time subscript, $R_{\mathrm{p}}$ represents the monthly return on a portfolio of IPOs, $R_{\mathrm{f}}$ represents the risk-free interest rate, as proxied by the 1-month Hong Kong Interbank Offer Rates on Hong Kong dollar deposits, and $R_{\mathrm{m}}$ is the market portfolio's rate of return, as proxied by the PACAP value-weighted market return for Hong Kong. The size factor, SMB, is constructed as follows: for each month all SEHK-listed firms are sorted by size into small and large portfolios, using the median value as the cutoff point; SMB is then given by the excess return of the valueweighted average return of the small portfolio minus the return of the large portfolio. The bookto-market ratio factor, HML, is constructed in the same manner as SMB and gives the difference in the returns of value-weighted portfolios of high and low book-to-market stocks. The estimate of the intercept, $\gamma_{0}$, provides a test of the null hypothesis that the mean monthly abnormal return on the calendar portfolio is zero. We estimate the above model using four IPO firm return series: 
Table 5

Investor demand as a predictor of IPOs' long-run returns

\begin{tabular}{|c|c|c|c|c|c|c|c|c|c|c|}
\hline & Intercept & Ratio & Size & Fund & IR & DIV & FIN & Ind & Year & $\mathrm{Adj}-R^{2}$ \\
\hline 1-Month $(t$-stat $)$ & $1.87(0.16)$ & $-0.01(-1.04)$ & $-4.27(-1.52)$ & $4.10(1.56)$ & $-0.10(-1.66)$ & $0.51(1.02)$ & na & Yes & Yes & 0.07 \\
\hline 6-Month ( $t$-stat) & $-28.19(-1.03)$ & $-0.08(-1.77)^{*}$ & $3.92(0.60)$ & $-1.74(-0.29)$ & $-0.19(-2.01)^{* * *}$ & $0.43(0.37)$ & na & Yes & Yes & 0.12 \\
\hline 12-Month ( $t$-stat) & $-46.34(-1.99)^{* * *}$ & $-0.10(-1.96)^{* * *}$ & $14.90(1.35)$ & $-8.11(-0.75)$ & $-0.13(-1.89)^{*}$ & $2.30(1.01)$ & $4.22(0.22)$ & Yes & Yes & 0.21 \\
\hline 24-Month ( $t$-stat) & $-68.39(-1.12)$ & $-0.05(-1.75)^{*}$ & $13.76(0.98)$ & $-9.28(-1.24)$ & $-0.08(-1.58)$ & $1.50(1.43)$ & $-5.34(1.60)$ & Yes & Yes & 0.16 \\
\hline 36-Month ( $t$-stat) & $-78.52(-0.88)$ & $-0.03(-1.47)$ & $8.11(0.33)$ & $-4.90(-0.21)$ & $-0.06(-1.21)$ & $1.44(0.87)$ & $-6.66(1.46)$ & Yes & Yes & 0.11 \\
\hline
\end{tabular}

Notes: The dependent variable is the buy-and-hold period excess returns of IPOs. Ratio is the oversubscription ratio. Size is the natural logarithm of the issuing firm's market capitalization (inflation adjusted to the 1993 value). Fund is the natural logarithm of the offering proceeds (inflation adjusted to the 1993 value). IR is the first-day return. DIV is the first annual cash dividend yield after IPOs FIN is the dummy variable accounting for the effect of new financing. Ind is a series of industry dummy variables and Year is a series of dummy variable indicating IPOs year.

* Significant at $10 \%$ level.

Significant at $5 \%$ level. 
Table 6

Calendar time portfolio regressions

\begin{tabular}{|c|c|c|c|c|c|}
\hline & Intercept & $R_{\mathrm{m}}-R_{\mathrm{rf}}$ & SMB & HML & $\mathrm{Adj}-R^{2}$ \\
\hline \multicolumn{6}{|l|}{ 6-Month calendar time portfolio } \\
\hline All IPOs $(t$-stat) & $-1.23(-1.56)$ & $0.56(3.24)^{* * *}$ & $0.51(3.12)^{* * *}$ & $-0.19(1.57)$ & 0.48 \\
\hline Low-demand IPOs ( $t$-stat) & $1.85(1.45)$ & $1.07(3.78)^{* * *}$ & $0.56(2.17)^{* *}$ & $0.42(1.66)$ & 0.51 \\
\hline Medium-demand IPOs ( $t$-stat) & $1.55(1.11)$ & $0.50(3.20)^{* * *}$ & $0.51(3.11)^{* * *}$ & $-0.11(-0.98)$ & 0.40 \\
\hline High-demand IPOs ( $t$-stat) & $-2.79(-1.63)$ & $0.79(2.97)^{* * *}$ & $0.79(2.08)^{* *}$ & $-0.45(-1.23)$ & 0.27 \\
\hline \multicolumn{6}{|l|}{ 12-Month calendar time portfolio } \\
\hline All IPOs ( $t$-stat) & $0.35(0.54)$ & $0.66(2.98)^{* * *}$ & $0.44(3.45)^{* * *}$ & $-0.17(-0.11)$ & 0.65 \\
\hline Low-demand IPOs ( $t$-stat) & $2.47(2.01)^{* *}$ & $1.02(3.01)^{* * *}$ & $0.40(3.12)^{* * *}$ & $0.12(0.23)$ & 0.62 \\
\hline Medium-demand IPOs ( $t$-stat) & $0.39(0.98)$ & $0.54(2.99)^{* * *}$ & $0.34(3.27)^{* * *}$ & $-0.02(-0.15)$ & 0.48 \\
\hline High-demand IPOs ( $t$-stat) & $-3.26(-1.98)^{* *}$ & $0.92(3.23)^{* * *}$ & $0.88(3.56)^{* * *}$ & $-0.37(-0.67)$ & 0.65 \\
\hline \multicolumn{6}{|l|}{ 24-Month calendar time portfolio } \\
\hline All IPOs ( $t$-stat) & $-1.23(-1.57)$ & $0.75(2.56)^{* * *}$ & $0.46(3.88)^{* * *}$ & $-0.13(-0.33)$ & 0.46 \\
\hline Low-demand IPOs ( $t$-stat) & $0.09(0.12)$ & $1.11(3.22)^{* * * *}$ & $0.55(3.18)^{* * *}$ & $0.05(0.02)$ & 0.37 \\
\hline Medium-demand IPOs ( $t$-stat) & $-1.37(-1.33)$ & $0.95(2.89)^{* * *}$ & $0.49(3.55)^{* * *}$ & $-0.07(-0.19)$ & 0.40 \\
\hline High-demand IPOs ( $t$-stat) & $-2.92(-1.88)^{*}$ & $0.89\left(2.56^{* * * *}\right.$ & $0.74(3.12)^{* * *}$ & $-0.28(-1.07)$ & 0.32 \\
\hline \multicolumn{6}{|l|}{ 36-Month calendar time portfolio } \\
\hline All IPOs ( $t$-stat $)$ & $-1.55(-1.66)$ & $0.80(3.22)^{* * *}$ & $0.66(3.75)^{* * *}$ & $-0.12(-1.08)$ & 0.38 \\
\hline Low-demand IPOs ( $t$-stat) & $-1.98(-1.78)^{*}$ & $0.96(2.99)^{* * *}$ & $0.43(2.78)^{* * *}$ & $0.33(1.56)$ & 0.29 \\
\hline Medium-demand IPOs ( $t$-stat) & $-1.49(-1.59)$ & $1.08(2.55)^{* * *}$ & $0.54(3.01)^{* * *}$ & $-0.09(-0.13)$ & 0.35 \\
\hline High-demand IPOs ( $t$-stat) & $-3.18(2.21)^{* *}$ & $0.94(2.87)^{* * *}$ & $0.66(2.99)^{* * *}$ & $-0.11(-0.88)$ & 0.31 \\
\hline
\end{tabular}

Notes: We run the three-factor regression model by using weighted least squares. The dependent variable is the monthly return on a portfolio of IPOs. $R_{\mathrm{f}}$ represents the risk-free interest rate. SMB is the difference in the returns of a value-weighted portfolio of small stocks and large stocks, and HML is the difference in the returns of a value-weighted portfolio of high book-to-market stocks and low book-to-market stocks.

** Significant at $5 \%$ level.

**** Significant at $1 \%$ level. 
(i) returns of all IPO portfolios, (ii) returns of the low-demand IPO portfolio, (iii) returns of the medium-demand IPO portfolio, and (iv) returns of the high-demand IPO portfolio. The number of IPOs in a portfolio is not constant over time, thus we rely on weighted least squares to account for the time-varying number of observations used to create calendar portfolios.

The results in Table 6 confirm the findings in Table 5. During the 6-month buy-and-hold period, the intercept for the low-demand IPO portfolio is positive while intercept for the high-demand IPO portfolio is negative, neither statistically significant at conventional significance levels. However, when the holding period is extended to 12 months, the average monthly excess return for the lowdemand IPO portfolio increases to a significant $2.47 \%$. By contrast, the average monthly excess return for the high-demand IPO portfolio decreases to significant $-3.26 \%$. For the 24-month holding period, we observe a positive but insignificant monthly excess return for the low-demand IPO portfolio, and a significant negative excess return for the high-demand IPO portfolio. Finally, results for the 36-month holding period reveal that both the low- and high-demand IPO portfolios underperform the market but the underperformance is much worse for the high-demand IPO portfolio. Thus, even controlling for market risk, size, and book-to-market factors, the evidence still suggests that the high-demand IPO portfolio underperforms both the market as well as its low-demand IPO counterpart in the long run.

\section{Discussion}

Overall, we find that IPOs' pre-offering investor demand is related to their aftermarket performance, both in the short run and in the long run. More importantly, the results reveal that investor demand is positively correlated with IPOs' first trading day returns, and that this relation becomes negative when longer-run performance is considered.

These findings are inconsistent with the information asymmetry and underpricing (or mispricing) hypotheses. For instance, although the findings from this study show that high-demand IPOs perform better on the first trading day, the results on high-demand IPOs' long-run underperformance conflict with the prediction suggested by the information asymmetry hypothesis, and the hypothesis proposed by Chowdhry and Sherman (1996), who establish a positive relation between investor demand (oversubscription) and IPO underpricing, is unable to explain the difference in the long-run performance between low- and high-demand IPOs. Indeed, a large oversubscription of a severely underpriced firm's shares is not likely to impact the firm's long-run performance because opening day trading could rapidly correct the mistake in the IPO's initial pricing. Thus, while the information asymmetry and underpricing hypotheses are useful in explaining the positive relation between investor demand and IPO initial returns, they are not able to fully explain the differential long-run performance of high- and low-demand IPOs.

The key finding of this paper, namely, that the negative relation between IPOs' first trading day returns and their long-run performance raises the very important question of whether underwriters and issuing firms really price an IPO below its true value at the offering, as most IPO underpricing theories hold. Our result on the relation is actually consistent with the speculative bubble hypothesis. Investor demand for an IPO is driven largely by investors' overoptimistic or overpessimistic reactions to pre-offering information about an IPO's prospects. That is, high investor demand for an IPO could be due to investor overoptimism about a firm's future. High demand is more likely to create a speculative bubble, temporarily pushing the stock's price above its true value. However, a speculative bubble would ultimately be corrected, in which case we would observe a relatively high positive short-run return followed by a negative long-run return for the IPO. In contrast, low investor demand for an IPO could be due to investor overpessimism about a firm's 
future. Since investors are more likely to underestimate the prospects of low-demand IPOs, these IPOs are more likely to experience relatively low returns on the first trading day. However, in the long-run, they can be expected to record relatively better performance as investors eventually learn the true value of these stocks. Thus, a speculative bubble-based explanation may reconcile the negative relation between first trading day returns and long-run performance.

\section{Concluding remarks}

Using a unique data set from the SEHK, which provides IPOs' oversubscription information at their offer prices, we examine the relation between IPOs' pre-offering demand and aftermarket performance between the 1993 and 1997 period. We find a strong relation between investor demand and both short- and long-run post-issue performance. First, we document that investor demand for IPOs is positively related to the IPOs' initial returns. The IPOs with high investor demand are significantly underpriced, while the IPOs with low investor demand are overpriced. Second, we find that the long-run size-adjusted excess returns of IPOs are negatively related to investor demand, with the high-demand IPO portfolio significantly underperforming and the lowdemand IPO portfolio outperforming the market in the long run. Overall, the paper finds that the IPOs with high investor demand have large positive initial returns but negative long-run excess returns, while the reverse is true for the IPOs with low investor demand. This evidence suggests that investor demand for an IPO is at least partly driven by investors' overreactions to pre-offering information about the IPO's prospects. Hence, while high- and low-demand IPOs are not priced at intrinsic values in early aftermarket trading, eventually their true values are reflected in their pricing.

\section{Acknowledgements}

The authors are grateful to anonymous referees, Jim Booth, Lena Booth, Rosita Chang, Souphala Chomsisengphet, Jay Ritter, Bhaskar Swaminathan, Greg Stone, Tong Yu, and the participants at the 2002 Global Finance Association meeting in Beijing and the University of Hawaii Finance Workshop for helpful comments and suggestions. The views expressed herein are those of the authors and not necessarily those of the Federal Reserve Bank of Chicago or the Federal Reserve System.

\section{References}

Affleck-Graves, J., Spiess, K., 1995. Underperformance in long-run stock returns following seasoned equity offerings. Journal of Financial Economics 38, 243-267.

Aggarwal, R., Rivoli, P., 1990. Fads in the initial public offering market. Financial Management (Winter), 45-57.

Barber, B., Lyon, J., 1997. Detecting long-run abnormal stock returns: the empirical power and specification of test statistics. Journal of Financial Economics 43, 341-372.

Chowdhry, B., Sherman, A., 1996. International differences in oversubscription and underpricing of IPOs. Journal of Corporate Finance 2, 359-381.

Cornelli, F., Goldreich, D., 2003. Bookbuilding: how informative is the order book? Journal of Finance 58, 1415-1443.

Hanley, K., 1993. The underpricing of initial public offerings and the partial adjustment phenomenon. Journal of Financial Economics 34, 231-250.

Ibbotson, R., 1975. Price performance of common stock new issues. Journal of Financial Economics 2, $235-272$.

Ibbotson, R., Jaffe, J., 1975. Hot issue markets. Journal of Finance 30, 1027-1042.

Kandel, S., Sarig, O., Wohl, A., 1999. The demand for stocks: an analysis of IPO auctions. Review of Financial Studies 12, 227-247. 
Ljungqvist, A., Nanda, V., Singh, R., 2007. Hot markets, investor sentiment, and IPO pricing. Journal of Business, in press.

Loughran, T., Ritter, J., 1995. The new issues puzzle. Journal of Finance 50, 23-51.

Loughran, T., Ritter, J., Rydqvist, K., 1994. Initial public offerings: international insights. Pacific-Basin Finance Journal 2, 165-199.

Lyon, J., Barber, B., Tsai, C., 1999. Improved methods for tests of long-run abnormal stock returns. Journal of Finance 54, 165-201.

McGuinness, P., 1992. An examination of the underpricing of initial public offerings in Hong Kong: 1980-1990. Journal of Business Finance and Accounting 19, 165-186.

McGuinness, P., 1993. The post-listing return performance of unseasoned issues of common stock in Hong Kong. Journal of Business Finance and Accounting 20, 167-194.

Michaely, R., Shaw, W., 1994. The pricing of initial public offerings: tests of adverse selection and signaling theories. Review of Financial Studies 7, 279-315.

Rajan, R., Servaes, H., 2002. The effect of market conditions on initial public offerings. Working paper, University of Chicago.

Ritter, J., 1984. The 'hot issue' market of 1980. Journal of Business 57, 215-241.

Ritter, J., 1991. The long-run performance of initial public offerings. Journal of Finance 46, 3-27.

Ritter, J., Welch, I., 2002. A review of IPO activity, pricing, and allocations. Journal of Finance 57, 1795-1828.

Rock, K., 1986. Why new issues are underpriced? Journal of Financial Economics 15, 187-212. 